\title{
Surface temperature measurement of flame spread using thermographic phosphors
}

\author{
Alaa Omrane*, Frederik Ossler, Marcus Aldén \\ Department of Combustion Physics \\ Ulf Göransson, Göran Holmstedt \\ Department of Fire Safety Engineering \\ Lund Institute of Technology, Lund University
}

\begin{abstract}
A technique based on remote measurements of surface temperature in connection to fires is presented. Pulsed ultraviolet laser radiation at $266 \mathrm{~nm}$ and $7 \mathrm{~ns}$ duration was used to excite a thermographic phosphor, $\mathrm{Mg}_{4} \mathrm{FGeO}_{6}$ : $\mathrm{Mn}$, which was adapted on the surface of the investigated material. The laser-induced emission from the phosphor was recorded. A calibration of the phosphorescence lifetime and spectral properties against temperature allowed surface temperature measurements between $25^{\circ} \mathrm{C}$ and $500^{\circ} \mathrm{C}$. The method was tested and compared with thermocouple measurements on burning materials such as lowdensity fiberboards and polymethylmetacrylate.
\end{abstract}

KEYWORDS: Surface temperature, thermographic phosphor, temperature measurement, flame spread

\section{INTRODUCTION}

In fire modeling, the calculation of surface temperature both before and after ignition is one of the most important tasks. As the surface is the border between the gas phase and the solid phase, the heat balance between the solid and the gas determines the surface temperature. If the surface temperature is correctly determined, both the direction and the size of the heat flow at the boundary can be calculated. The measurement of surface temperature enables the knowledge of when a product will ignite and how much heat release that will be generated when it is burning since that is a function of the heat flow. In addition one can estimate how much heat that is lost from the gas in the room to the surrounding construction and contributes to the thermal radiation, which determines the risk for flashover and flame spread.

In order to obtain a good prediction of the ignition and flame spread, surface temperatures are often measured during fire tests [1]. Based on these measurements, further analyses can be performed determining, e.g. The heat flux to the wall, the thermal properties of the solids, pyrolysis temperatures, emissivities and heat of vaporisation.

Since the surface temperature is so important for the calculations, it is crucial that the estimate of the surface temperature is as correct as possible. The most common ways to determine the surface temperature are either to measure the surface temperature with

* To whom correspondence should be sent.

Electronic mail: alaa.omrane@forbrf.lth.se

FIRE SAFETY SCIENCE--PROCEEDINGS OF THE SEVENTH INTERNATIONAL SYMPOSIUM, pp. 141-152 
thermocouples or to calculate the surface temperature using known thermal properties of the solid. As the thermal properties normally are heavily temperature dependent and often have been determined using thermocouples, the surface temperature estimation may have a poor accuracy (constitute uncertainties in the order of $100^{\circ} \mathrm{C}$ ). This can explain the very different ignition temperatures reported for similar experiments [2].

\section{TRADITIONAL SURFACE TEMPERATURE MEASUREMENT}

Surface temperatures are normally measured by using probe techniques, most often thermocouples [3]. Thermocouples are cheap and cover a width range of temperatures, which makes them suitable to many applications.

For certain applications thermocouples have, however, some drawbacks. Thermocouples always indicate their own temperature and not the surface temperature. It is therefore necessary to use the thermocouple in such a way that the difference in temperatures between the surface of the object and the thermocouple is as small as possible $[1,4,5]$. This is normally achieved by using thin fragile thermocouples applied to the object with a technique that ensures that the thermocouple is in contact with the object surface $[6,7]$, or by deriving the surface temperature from calculations of ignition or flame spread [8, 9].

For a thermocouple in a gas the radiative and convective parts of the heat balance are competing whereas on a surface the conductive heat transfer is dominating. Since the temperature gradient close to the surface is very strong for products subjected to flames, it is very important that the thermocouples used for measuring the surface temperature are positioned correctly. With temperature gradients on the order of $50 \mathrm{~K} / \mathrm{mm}$ both in the solid material and in the boundary layer, it is obvious that the results are very sensitive to the mounting technique.

Thermocouples might also influence the flow field and the temperature field around them. However, this is for many applications not a considerable problem if high accuracy is not required. For a product that is pyrolysing, melting, cracking or burning, the position of the thermocouple related to the surface may change leading to problems due to correctly defining the position of the thermocouple [8].

\section{IR-METHODS}

There are also other methods for temperature measurements that are non-intrusive e.g. those using pyrometers that measure the blackbody radiation from the surface. This method is good for many purposes but has problems dealing with varying emissivity and radiation from flames interfering with the surface radiation. To minimise these problems with flame emission, Urbas and Parker [6] used a narrow band IR-detector to measure blackbody emission in the wavelength region 8-12 $\mu \mathrm{m}$. The method showed good agreement with thermocouple measurements. However, measurements of blackbody radiation in luminous flames will always yield unknown errors since the surface emissivity and interfering radiation from flames in the studied wavelength regions are not known. As an example the blackbody radiation from a flame with a temperature of 1200 $\mathrm{K}$ and an emissivity of 0.015 in front of a $600 \mathrm{~K}$ wall surface will produce an error in the order of $10 \mathrm{~K}$ of the thermal radiation in $8-12 \mu \mathrm{m}$ band. This is in agreement with the calculations done by Arakawa/Saito/Gruver [10] that according to Urbas and Parker [6 ] 
correspond to a flame of about $2 \mathrm{~cm}$ thickness on a polymethylmethacrylate (PMMA) surface.

\section{THE PHOSPHORESCENCE TECHNIQUE}

In recent years a new technique has been developed for remote measurements of surface temperature. It is used in scientific and industrial applications of surface thermometry to complicated geometries, e.g., rotor engines [11], turbine engines [12], and also in medicine. Other quantities, relevant to the scientific and engineering community such as heat flux through a surface have also been investigated $[13,14]$.

During the last years, as the applications of phosphor have expanded, some attempts have been made in combustion environment [16]. A useful review article [15] could be a good assistance as an introduction to the subject of phosphor thermometry.

A phosphor becomes highly fluorescent or phosphorescent when it is excited by a appropriate source, e.g. an electron beam or ultraviolet radiation. Typically the emission is in the visible region and has a lifetime of the order $10^{-3} \mathrm{~s}$. The phosphor consists of a host material and a doping agent from which the light is emitted. A large number of different phosphors are produced today covering a large band of temperatures from cryogenic temperatures up to $1400-1600^{\circ} \mathrm{C}$ or higher making them suitable to many applications. Each selected phosphor is very sensitive in a specific range of temperature exhibiting an accuracy of the order $1-5^{\circ} \mathrm{C}$.

Thermographic phosphors have normally been used for hard non-combustible materials such as steel or concrete. For those surfaces the phosphor can be applied to the surface, and only a very thin layer is required which also ensures that the phosphor layer does not influence the flow.

The phosphorescence method described in this article has many advantages that makes it interesting for fire testing.

- The method is non-intrusive which allows non-disturbed gas movements close to the surface.

- It has a fast response to thermal changes.

- The method is fast. There can be many measurements done every second.

- The accuracy is good. Measurements can be made with an accuracy of less than $5^{\circ} \mathrm{C}$.

- The signal is based on relative values of the readout so that absolute calibrations are not needed

- The laser-induced phosphorescence is of short duration, fractions of a second. This makes it possible to use a gating procedure to reduce background emission.

\section{EXPERIMENTAL WORK}

In order to correlate the phosphorescence to temperature, a series of calibration measurements were performed. Fig. 1 shows the set-up of a calibration measurement using a laser for excitation, fibers for guiding light, filters for increasing signal to background ratio, and detectors for acquiring the phosphorescence emission.

The phosphor material used was $\mathrm{Mg}_{4} \mathrm{FGeO}_{6}: \mathrm{Mn}$, Mn being the activator. The maximum efficiency has been specified for a Mn: Ge mole fraction of 4:1. In the experiments low laser intensity, $50 \mu \mathrm{J}$, was enough to obtain phosphorescence. A power dependence test 
on the intensity of the emission did not show any noticeable variation of the phosphor lifetime while varying the laser power between $50 \mu \mathrm{J}$ and $1 \mathrm{~mJ}$.

The phosphor was excited by the fourth harmonics $266 \mathrm{~nm}$ of a Nd: YAG laser with pulse duration of about $7 \mathrm{~ns}$ and a repetition rate of $10 \mathrm{~Hz}$. The laser light was focused into a fiber with a diameter of $0.7 \mathrm{~mm}$ and transmitted to the phosphor in the test cell at the other end of the fiber. The subsequent emission was collected by two other fibers, which individually supplied a spectrograph connected to an intensified charged coupled,

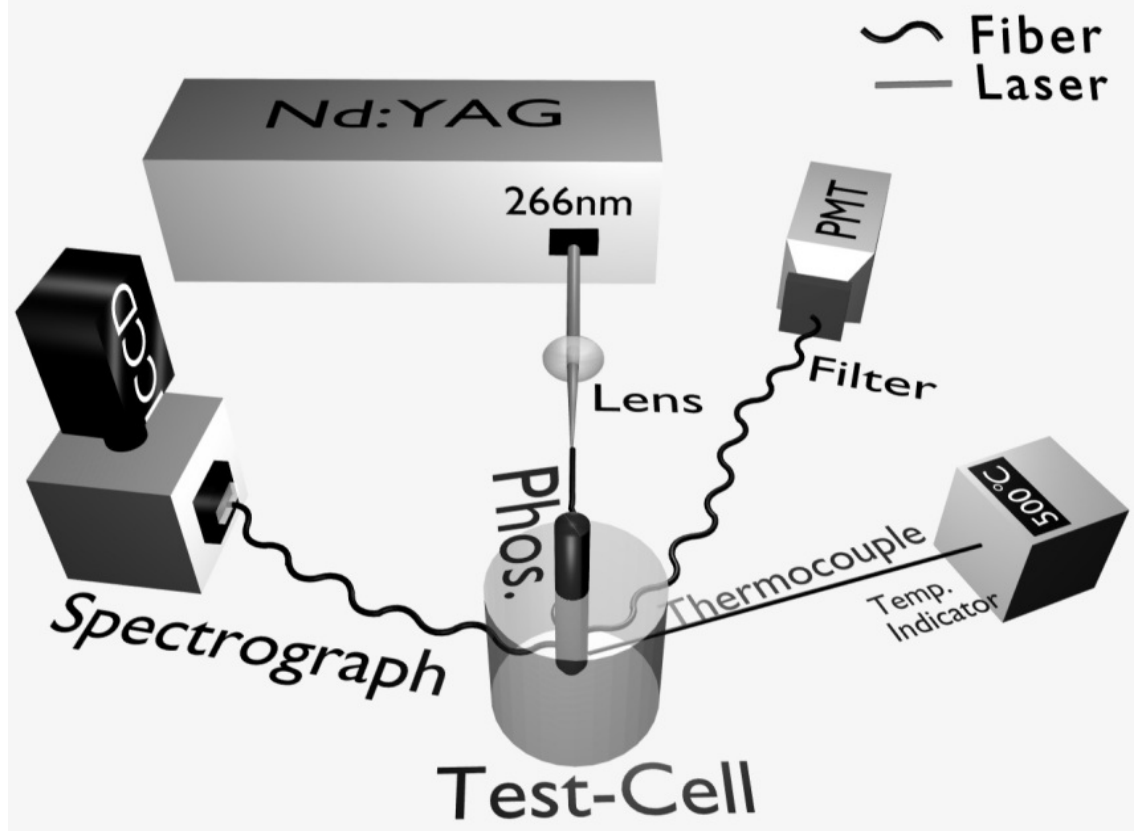

Fig. $1 \quad$ Calibration set-up using a spectrograph, ICCD, laser, PMT, thermocouple and the test cell.

device (ICCD), and a photomultiplier tube (PMT), for spectrally and temporally resolved measurements respectively.

The test measurements were done inside a cell used for the calibration. A rod of the same material as the cell (inox) was coated at one end with a mixture (50:50)\% of the phosphor and a ceramic cement (cerastil-c) to a thickness of approximately $200 \mu \mathrm{m}$. The rod was inserted into the cylindrical chamber of the cell, which had one small input port for the laser beam and two output ports for the emission. The radiation was guided by quartz fibers $(\varnothing=0.7 \mathrm{~mm})$. A calibrated thermocouple with an accuracy of $\pm 1{ }^{\circ} \mathrm{C}$ was used to measure the temperature close to the phosphor inside the cell. The temperature of the wall of the cylinder could be changed between room temperature and $800^{\circ} \mathrm{C}$ using heating wires. 
Two techniques for calibrating the collected emission based on temporally [15] and spectrally resolved measurements were used. Fig. 2 shows the temporally resolved detection where the lifetime was measured at different temperatures. The lifetime decreased when the temperature was increased.

The decay curves showed a sharp peak followed by an exponential decay. An iterative curve fitting procedure was used to extract the lifetime and thus the temperature. Fig. 3 shows the resulting lifetime calibration for the selected phosphor. For a temperature range between $400-500^{\circ} \mathrm{C}$, the quenching rate increased. Therefore the intensity and lifetime decreased drastically with temperature exhibiting higher phosphor sensitivity to temperature variation and thereby higher measurement accuracy. The selected phosphor was therefore considered for measurements of surface temperature of burning materials.

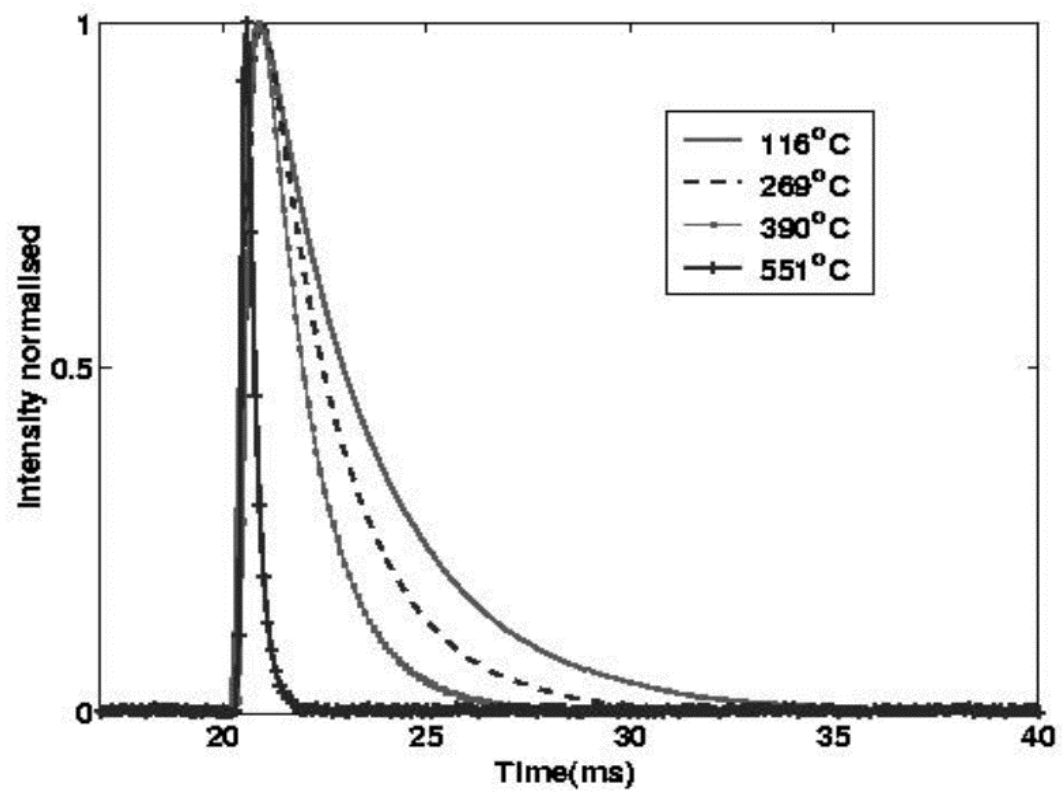

Fig. 2 Phosphorescence decays measured at different temperatures. The lifetime becomes shorter when the temperature increases.

In well-controlled experiments the temperature was then obtained from the measured lifetime and the previously performed calibrations.

The spectrally resolved technique $[17,18]$ is based on monitoring the emission versus wavelength. A typical spectrum of $\mathrm{Mg}_{4} \mathrm{FGeO}_{6}$ : Mn with a dispersion of $0.7 \mathrm{~nm}$ is shown in Fig. 4 where the emission covers the range $590-730 \mathrm{~nm}$. At high temperature, the non-radiative deexcitation rate (transfer of energy without light emission) dominated by thermal relaxation (transfer of energy into lattice vibrations) increased. The non-radiative deecitation rate is strongly dependent on temperature resulting in a decrease of emission efficiency and shortening of the emission decay time at high temperature, although not at the same rate for the different emitted wavelength. The advantage of this technique is that 
the ratio between the two apparent peak intensities of the phosphor is only dependent on temperature. Following a UV excitation the emission signal, $S_{j}$, can be represented by:

$S_{j}=C_{j} T_{e} N_{j}(T) \tau_{j} I$

Where $C_{j}$ is the detection efficiency for the $j_{t h}$ transition $T_{e}$ is the camera exposure time, $\mathrm{Nj}(\mathrm{T})$ is the temperature dependent quantum efficiency for the $\mathrm{j}_{\mathrm{j}}$ transition, $\tau_{\mathrm{j}}$ is the optical filter transmission and $\mathrm{I}$ is the intensity of the laser beam. By rationing the signal for the two different transitions, the resulting value is only dependent on temperature as:

$$
\frac{S_{j+1}}{S_{j}}=K \frac{N_{j+1}(T)}{N_{j}(T)}
$$

Where $K$ is a constant. Fig. 3 also shows the peak-to-peak ratio for different temperatures up to $550^{\circ} \mathrm{C}$. As the non-radiative rate increases when increasing temperature, the signal to background decreases. The precision of temperature determination in the case of the ratio technique is found to be $5-10{ }^{\circ} \mathrm{C}$ while the lifetime technique showed a higher precision of $1-5^{\circ} \mathrm{C}$.

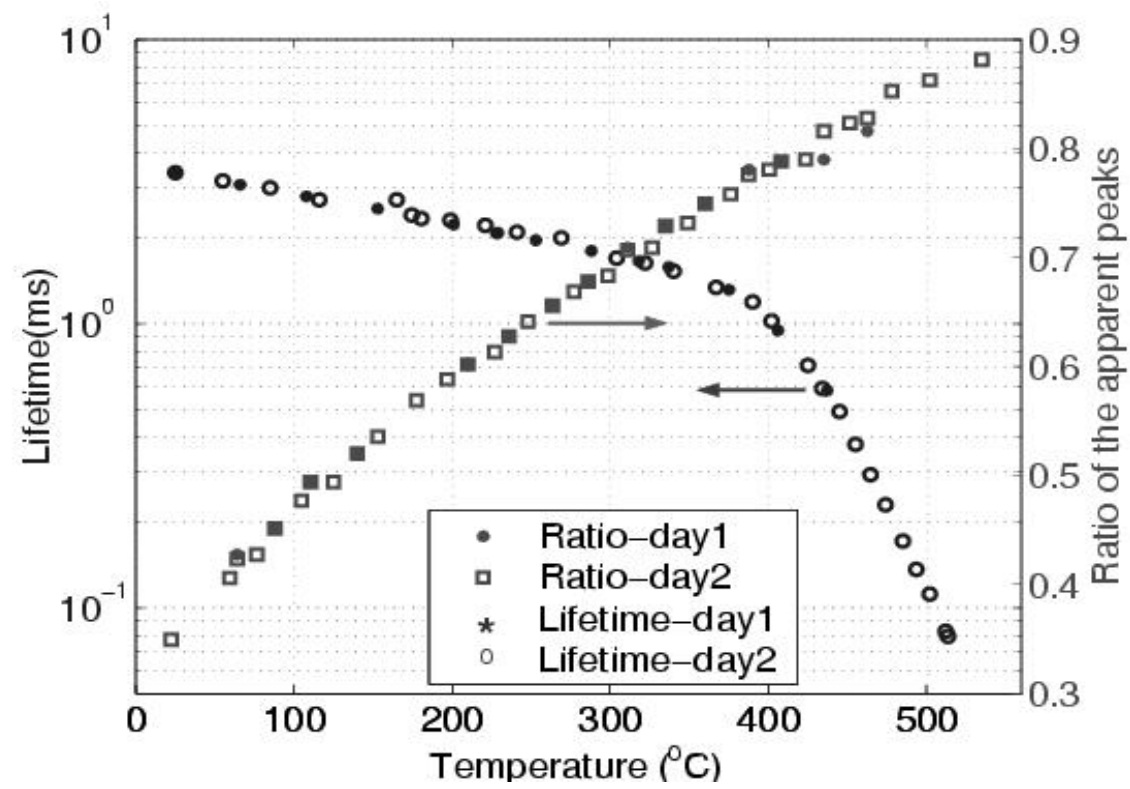

Fig. 3 Calibration of temperature against the lifetime and spectral intensity ratio of the phosphorescence. The left axis shows the lifetime versus temperature on a logarithmic scale for two different calibrations days. The right axis the relative intensity ratio of the peaks of the spectrally resolved emission against temperature. 


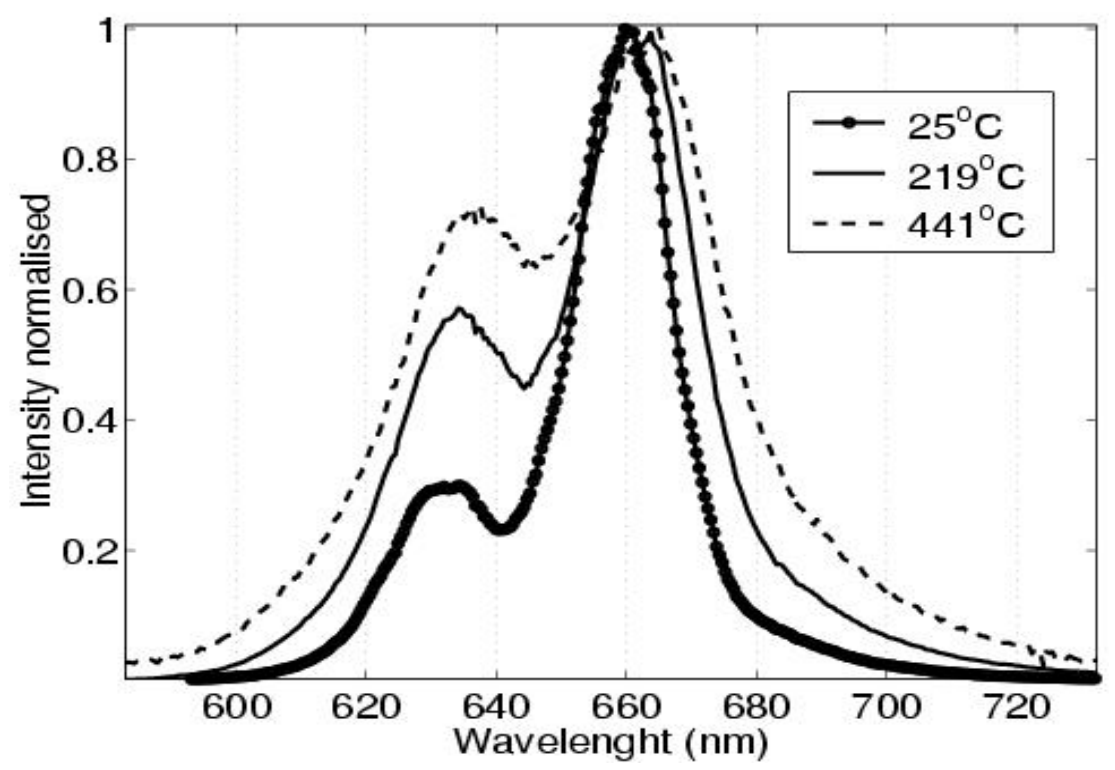

Fig. 4 Spectral profiles of the phosphorescence emission of $\mathrm{Mg}_{4} \mathrm{FGeO}_{6}: \mathrm{Mn}$ at different temperatures, The intensity is normalised in order to illustrate the temperature sensitivity of the atomic line at $631 \mathrm{~nm}$.

\section{FLAME SPREAD EXPERIMENT}

Our intention was to use the thermographic phosphors on combustible materials during heat-up, and also during combustion, which may introduce some additional problems. To enable measurements during combustion, the phosphor has to be applied not only to the surface but also further into the material. The idea is that when the product is burning, and the surface material is consumed new phosphor will appear from inside.

In the tests, a small hole, $(\phi=1 \mathrm{~mm})$, was drilled in the solid and then filled with the phosphor to a density close to that of the material. No cement or similar substance was used. Earlier pre-tests on a wood/glue/phosphor mixture-filled hole showed good performance at the beginning of the test but did, however, not burn as a standard wooden board.

Small-scale experiments were carried out where the flame spread on a vertical surface, (5 $\mathrm{cm}$ wide, $12 \mathrm{~cm}$ high and $1 \mathrm{~cm}$ thick) was studied see Fig. 5. The board was wet by heptane or ethanol at the bottom and then ignited. Convection and radiation from the flame heated the board. The laser light was directed onto the phosphor filled hole, which was positioned on the centerline about $25 \mathrm{~mm}$ from the top end. A high temperature resistant quartz fiber mounted close to the measured surface was used to transmit the emitted signal to a photomultiplier detector. The optical fiber works well as a light guide in harsh environment and could be easily protected if high flame temperatures (more than $1000{ }^{\circ} \mathrm{C}$ ) is suspected. The phosphorescence signal was stored on the computer for subsequent processing. The spectral and the temporal methods are relatively dependent on the signal intensity and therefore don't extensively suffer from background emission 
although a high signal to background ratio is usually preferred. In this measurement only temporal based method was used where phosphorescence signal decay was analyzed to extract lifetime and per-consequent temperature information.

A measurement test was done on a non-combustible board where a comparison was made between the phosphor technique and results from a thermocouple. The effect of different fuels e.g. flame luminosity on the acquisition data, was also investigated by testing two fuels, alcohol and heptane. The flames from heptane released more soot and heat radiation than the alcohol. The luminous sooty flame from heptane caused a decrease in the signal to noise ratio. Even though the signal to background ratio could be improved using optical filters it was decided to use only the alcohol in the following measurements.

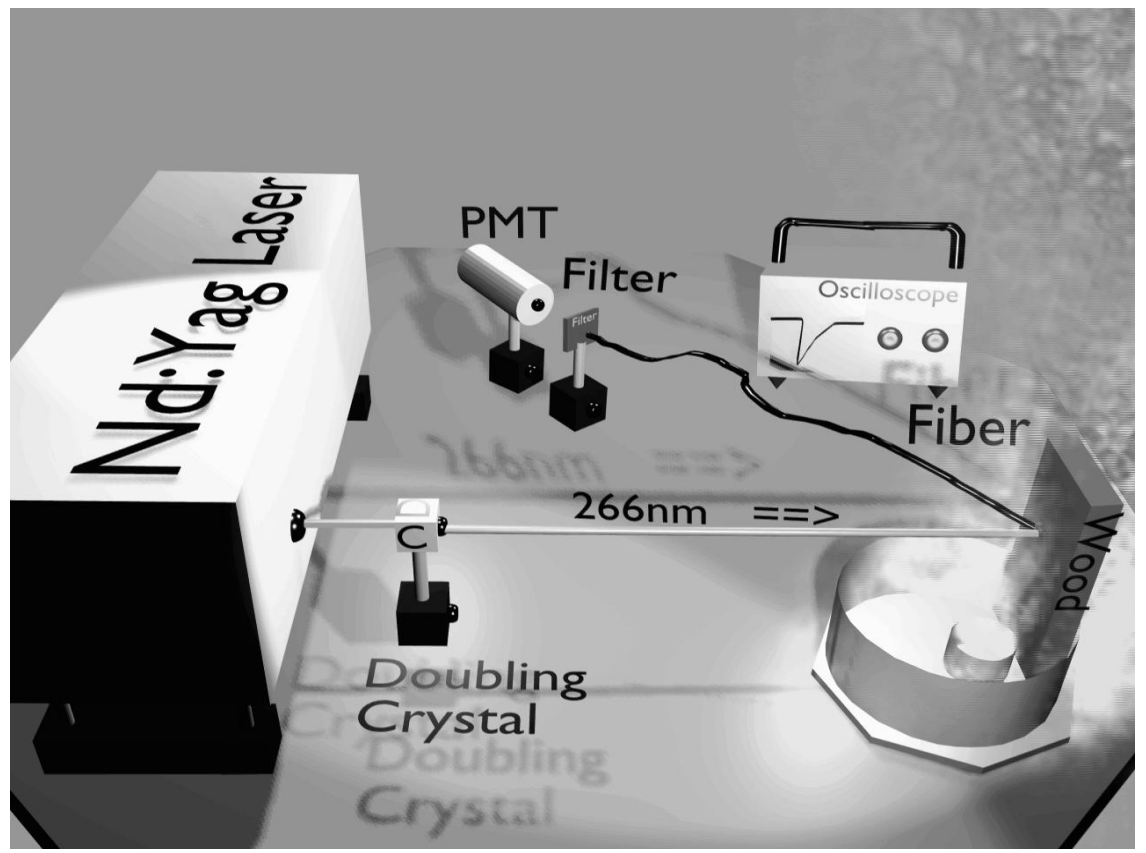

Fig. 5 The experimental setup: The laser beam is pointing at the phosphor spot on the combustible surface. After excitation the phosphor emission is measured by a photomultiplier connected to a fast oscilloscope for signal digitizing and storage.

\section{LOW DENSITY FIBER BOARD}

Two tests were done on identical low-density fiberboards. This product was a good material for our test measurements because it produced only small amounts of soot and burned homogeneously and well controlled during combustion. The dimensions of the test material were as given above. The phosphor was introduced into a depth of $5 \mathrm{~mm}$ in a hole of 1-mm diameter to maintain the phosphor present while the material was burning. The one millimeter hole diameter was kept small to avoid interaction between the 
phosphor and chemical reactions occurring during combustion. The test results are shown in Fig. 6. A rapid increase in temperature during the burning process was seen during the first seconds after ignition. In both tests temperature leveled out at around $400^{\circ} \mathrm{C}$, which was the highest temperature reached at the surface. The only difference between the two tests was the velocity of the burning process caused by the different ignition conditions.

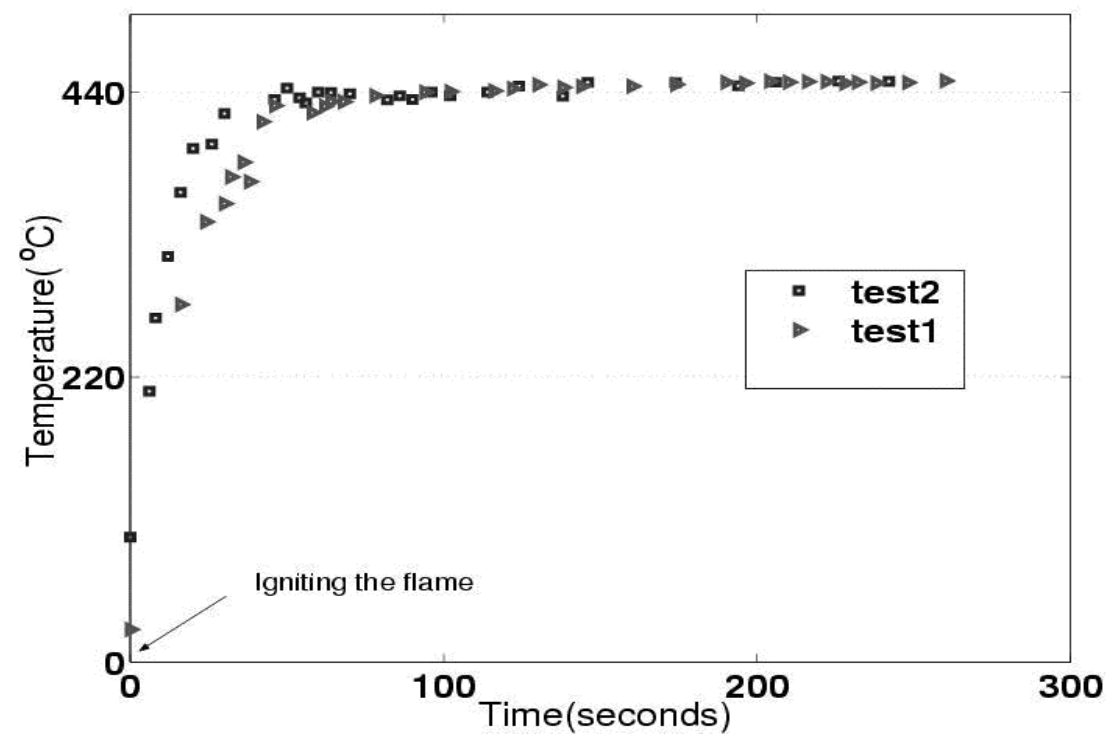

Fig. 6 Two tests on identical low-density fiber boards are showed. Measurements of surface temperature of $450^{\circ} \mathrm{C}$ were reached during the burning process initiated by an ethanol fuel.

\section{PMMA}

The surface temperature was also measured on PMMA using both phosphorescence and a thermocouple. A pool of burning alcohol ignited the PMMA, the use of this fuel is helpful for monitoring the ignition process of the material because it is has a modest heat release compared to heptane. The results are shown in Fig. 7 where the signal recorded is plotted versus time from the moment of ignition of the pool. A surface temperature between 380 and $400^{\circ} \mathrm{C}$ was measured during the burning phase. PMMA ignition temperature could be seen around $275^{\circ} \mathrm{C}$, about 810 seconds after the ignition of the pool. This does very well agree with other measurements $[19,20]$. 


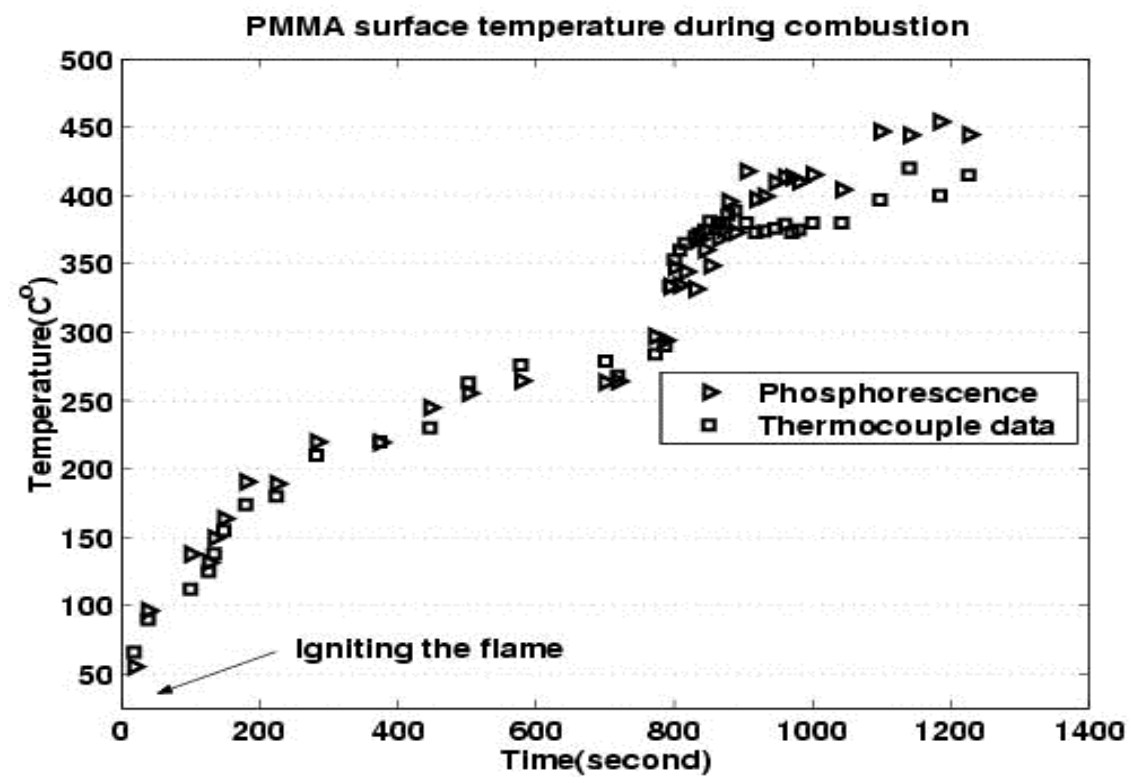

Fig. 7 The development of PMMA surface temperature versus time from ignition of the heat source(ethanol). Results from measurements with thermographic phosphors and thermocouples are compared. The ignition temperature of PMMA is at about $270 \mathrm{deg} C$.

\section{CONCLUSION AND FUTURE WORK}

Surface temperatures were measured at the surface of the burning medium using thermographic phosphors. Ignition time and surface temperature at that moment were measured during the combustion when an alcoholic fuel was used for heating the sample

The demonstrated thermographic-phosphor technique has shown to be effective under non-sooting conditions. Interference by soot generated emission should be avoided to improve the signal to noise ratio, e.g. by studying the fluorescence from the phosphors on a short exposure time or using a phosphor that emits in the UV region.

This technique will be extended to two-dimensional measurements of temperature in nonsooty environment. Further studies will also be done to improve the application of the substance onto the sample.

\section{ACKNOWLEDGMENTS}

We thank CECOST, Centre of Combustion Science and Technology, and Centre of Competence in Combustion Processes for funding. 


\section{REFERENCES}

[1] W.J. Pitts. , “Temperature Measurements in Fires” ; Proceedings of an International Workshop on Measurement Needs for Fire Safety; 2000 NISTIR 6527.

[2] J. Fangrat, Y. Hasemi, M. Yoshida, and T.Hirata, "Surface Temperature at Ignition of Wooden Slabs” ; Fire Safety Journal 27:3, 249-259, (1996).

[3] P.R.N Childs, J.R. Greenwood, and C.A. Long, "Review of Temperature Measurement" ; Thermo-Fluid Mechanics Research Centre, Univ. of Sussex, Brighton, UK; Review of Scientific Instruments 71:8, 2959-2978, (2000).

[4] M.C. Luo, "Effects of Radiation on Temperature Measurement in a Fire Environment" ; Journal of Fire Sciences 15:6, 443-461, (1997).

[5] N. Keltner, "Fire Test Furnace Characterization Unit" ; Proceedings of an International Workshop on Measurement Needs for Fire Safety; NIST-IR 6527, 2000 .

[6] J. Urbas and W. J. Parker, "Surface Temperature Measurements on Burning Wood Specimens in The Cone Calorimeter and the Effect of Grain Orientation” ; Fire and Materials 17, 205-208, (1993).

[7] B. Fredlund, "A Model for Heat and Mass Transfer in Timber Structures During Fire” ; Ph D Thesis, Dep of Fire Safety Engineering; Lund University, 1988.

[8] M.L. Janssens, "Fundamental Thermophysical Characteristics of Wood and Their Role in Enclosure Fire Growth" ; Ph D Thesis, National Forest Products Association USA; University of Gent Belgium, 1991.

[9] M.J. Spearpoint and J.G. Quintiere, "Predicting the Burning of Wood Using an Integral Model”; Combustion and Flame 123:3, 308-325 (2000).

[10] A. Arakawa, K. Saito, and W. A. Gruver, “Automated Infrared Imaging Temperature Measurement with Application to Upward Flame Spread Studies. Part I "; J. of Combustion and Flame. 1993;Vol 92.

[11] B. W. Noel, S. W. Allison and M. R. Cates, "Monitoring Permanent-magnet Motor Heating with Phosphor Thermometry" ; IEEE Transaction on Instrumentation and Measurement 37:4, 637-641 (1988).

[12] S. Alaruri, T. Bonsett, A. Brewington, E. McPheeters and M. Wilson, "Mapping the Surface Temperature of Ceramic and Superalloy Turbine Engine Components Using Laser-Induced Fluorescence of Thermographic Phosphor"; Optics and Lasers in Engineering 31:5, 345-351 (1999).

[13] B. W. Noel, W. D.. Turley, and K. W. Tobin, Los Alamos National Laboratory Technical Report No. LA-CB-91-0182, April 1991. 
[14] J. P .Hubner, B. F. Carroll, K. S. Schanze, "Heat transfer measurements in hypersonic flow uding luminescent coating techniques"; AIAA Journal 39:4, 654659 (2001).

[15] S.W. Allison, G.T. Gillies, "Remote thermometry with thermographic phosphors :Instrumentation and applications" ; Review of Scientific Instruments 68:7, 1-36, (1997).

[16] R. L. Vander Wal, P. A. Householder and T. W. Wright II, "Phosphor Thermometry in Combustion Applications" ; Applied Spectroscopy 53:10, 12511258 (1999).

[17] R.H. Krauss, R.G. Hellier and J.C. McDaniel, "Surface Temperature Imaging Below 300K Using La2O2S:Eu", Applied Optics 33:18, 3901-3904 (1994).

[18] R. Marino, B. Westring, G. Laufer, R. H. Krauss and R. Whitehurst, "Digital Strain and Temperature Imaging Technique” ; AIAA Journal 37:9, 1097-1101 (1999).

[19] C. Beyler, M. Hirschler, "Thermal Decomposition of Polymers"; SFPE Handbook of Fire Protection Engineering, 2nd ed., 1995.

[20] T.-H. Tsai, M.-J. Li, I.-Y. Shih, R. Jih, S.-C. Wong. ,"Experimental and Numerical Study of autoignition and Pilot Ignition of PMMA Plates in a Cone Calorimeter"; Combustion and Flame 124:3, 466-480 (2001). 